\title{
ESTRATÉGIAS PARA O ENSINO DE QUÍMICA EM NÍVEL MÉDIO PROFISSIONAL E TECNOLÓGICO PRESENTES EM ARTIGOS CIENTÍFICOS
}

\section{ARTIGO ORIGINAL}

CORREA, Marcia Lopes ${ }^{1}$, DIAS, Claudio Alberto Gellis de Mattos², FECURY, Amanda Alves ${ }^{3}$, OLIVEIRA, Euzébio de ${ }^{4}$, DENDASCK, Carla Viana ${ }^{5}$, FERNANDES, Erlyson Farias ${ }^{6}$

CORREA, Marcia Lopes. Et al. Estratégias para o ensino de química em nível médio profissional e tecnológico presentes em artigos científicos. Revista Científica Multidisciplinar Núcleo do Conhecimento. Ano 06, Ed. 03, Vol. 07, pp. 113123. Março de 2021. ISSN: 2448-0959, Link de acesso: https://www.nucleodoconhecimento.com.br/educacao/nivel-medio, $\quad$ DOI: 10.32749/nucleodoconhecimento.com.br/educacao/nivel-medio

\section{RESUMO}

O ensino de Química não é uma tarefa tão fácil para docentes formados em tempos contemporâneos. O processo de atualização do seu currículo deve ser uma constante na profissão. $O$ docente precisa planejar suas aulas com uma linguagem que possa facilitar para o aluno a compreensão dos conteúdos explanados. Uma das maneiras de se trabalhar química poderia ser com o estudante participando de

\footnotetext{
${ }^{1}$ Acadêmica do Curso de Pós-Graduação em Ensino de Química do Instituto Federal do Amapá (IFAP).

2 Biólogo, Doutor em Teoria e Pesquisa do Comportamento, Professor e pesquisador do Curso de Licenciatura em Química do Instituto de Ensino Básico, Técnico e Tecnológico do Amapá (IFAP) e do Programa de Pós Graduação em Educação Profissional e Tecnológica (PROFEPT IFAP).

${ }^{3}$ Biomédica, Doutora em Doenças Topicais, Professora e pesquisadora do Curso de Medicina do Campus Macapá, Universidade Federal do Amapá (UNIFAP).

${ }^{4}$ Biólogo, Doutor em Doenças Topicais, Professor e pesquisador do Curso de Educação Física da, Universidade Federal do Pará (UFPA).

${ }^{5}$ Teóloga, Doutora em Psicanálise, pesquisadora do Centro de Pesquisa e Estudos Avançados- CEPA.

${ }^{6}$ Químico, Mestre em Química (UFPA), Professor e pesquisador do Curso de Licenciatura em Química do Instituto de Ensino Básico, Técnico e Tecnológico do Amapá (IFAP).
}

RC: 78586

Disponível em: https://www.nucleodoconhecimento.com.br/educacao/nivel-medio 
forma ativa no processo. Os agroquímicos são temas exequíveis de serem mediados desta forma e podem potencialmente aumentar o interesse dos discentes pela disciplina. Este artigo pretende Identificar as estratégias para o ensino de química em nível médio profissional e tecnológico presentes em artigos científicos com a temática "agrotóxicos". A metodologia escolhida para este estudo foi de abordagem qualitativa centrada em preocupar-se com a realidade. A observação deste breve levantamento permite concluir que o ensino de química em turmas de segundo grau pode e deve estar relacionado a área da pesquisa e da divulgação científica; existem diversas ferramentas didáticas que possibilitam maneiras mais assertivas relacionadas ao ensino de química; e relacionar o conteúdo de química a assuntos interdisciplinares e específicos, como agrotóxicos, pode auxiliar a melhor compreensão dos conteúdos de química em estudantes do ensino médio.

Palavras-chave: Ensino médio, Química, EPT, Agrotóxico.

\section{INTRODUÇÃO}

Mediar o ensino de Química não é uma tarefa tão fácil para docentes formados em tempos contemporâneos, pois Salgado, Passos e Ribeiro (2018) ratificam que ter conhecimento Químico não é suficiente para se garantir sucesso no processo de ensino-aprendizagem, no consenso que ensinar requer estudo, planejamento, paciência. Zabala (1998 apud Salgado et al. (2018) afirma que não se aprende conceitos se não conseguimos compreender o significado do que está sendo construído naquele momento. No consenso, o ensino deve garantir uma aprendizagem significativa para o estudante, possibilitando assim a construção de seus próprios conceitos.

Nessa perspectiva para (Ribeiro et al., 2020) o docente deve estar preparado para as constantes mudanças no cenário educacional. Nesse sentido, o processo de atualização do seu currículo deve ser uma constante na profissão do docente. Vale explicitar que estes conhecimentos devem ser trabalhados em sala de aula, e assim,

$\mathrm{RC}: 78586$

Disponível em: https://www.nucleodoconhecimento.com.br/educacao/nivel-medio 
permitir às discentes metodologias que possam aumentar seu interesse e estimular suas habilidades e competências, até mesmo fora de sala de aula.

E diante da atual situação que estamos inseridos apontam Santos e Schntzler (2010) com problemas ambientais frequentes e consequentes problemas de saúde na população, é de extrema importância que o professor/a esteja disposto a conhecer o contexto histórico e cultural dos estudantes, pois somente assim, poderá propor estratégias metodológicas significativas, considerando, a realidade local e cultural destes alunos/as. Afirmam Ribeiro et al. (2020)que a formação do aluno/a deve ser crítica e participativa, rompendo desta forma com o ensino tradicional, possibilitando assim, melhorar sua convivência no local e ao redor onde vive. Assim, a Ciência, Tecnologia, Sociedade e Ambiente (CTSA) torna-se uma forte ferramenta.

A ciência, para Hodson (2018), é intrínseca e é definida como uma prática social distinta e está disseminada no meio político, econômico e social, gerando, portanto, grande impacto sobre suas prioridades e decisões.

Não obstante Sousa e Simões (2016) afirmam que o docente deve estar preparado para a realidade do meio educacional brasileiro e as constantes mudanças que 0 meio está sujeito, na premissa de formar indivíduos cada vez mais conscientes a viverem em sociedade. Nessa perspectiva, a escola deve incentivar o docente e contribuir para que a educação ambiental esteja inserida no processo de ensinoaprendizagem. Salienta-se ainda que, deve fazer parte do currículo estudantil. Ou seja, inserida em todas as disciplinas, pois o tema pode ser trabalhado com diversos conteúdos e de diversas maneiras em sala de aula (Leite, 2015).

Para Santos e Schntzler (2010) o docente precisa planejar suas aulas com uma linguagem que possa facilitar para o aluno a compreensão dos conteúdos explanados, no intento, que pessoas aprendam de formas diferentes, e em contextos diferentes. Conforme Chassot (2000) a educação deve ser engajada na realidade do discente, de modo, que percebam que ela está presente nas situações 
mais simples da vida, abandonando assim o dogmatismo e o abstracionismo, no viés que a Química deve ter uma linguagem universal.

Para Moreira e Masini (1982) existem dois tipos de aprendizagem: a mecânica e a significativa, na significativa o conhecimento prévio do educando é valorizado e contribui para o seu processo de aprendizagem, possibilitando tornar o discente mais interessado, responsável e confiante. Os conceitos mais amplos se superpõem a conceitos com menor poder de extensão. Em contrapartida, a aprendizagem mecânica a informação é relacionada de forma arbitrária e imparcial em que o estudante se comporta como ser passivo e não participativo do processo.

Uma das maneiras de se trabalhar química poderia ser proporcionando consciência ambiental de forma dialogada, onde o estudante pode participar de forma ativa no processo. Os agroquímicos são temas exequíveis de serem mediados desta forma, sem falar que podem potencialmente aumentar o interesse dos discentes pela disciplina, e concomitantemente, melhorar a relação destes com o meio ambiente (Sousa e Simões, 2016).

\section{OBJETIVO}

Identificar as estratégias para o ensino de química em nível médio profissional e tecnológico presentes em artigos científicos com a temática "agrotóxicos".

\section{MÉTODO}

A metodologia escolhida para este estudo foi de abordagem qualitativa centrada em preocupar-se com a realidade, embora a pesquisa que compreende o lócus esteja atrelada ao quantitativo, a sua natureza é de base interpretativa. Para Moreira e Schittler (2016) essa abordagem centraliza em se preocupar com o meio explicativo das relações sociais, na perspectiva dos estudantes.

RC: 78586

Disponível em: https://www.nucleodoconhecimento.com.br/educacao/nivel-medio 
Desse modo, a pesquisa é de revisão bibliográfica com base exploratória, buscando dados em trabalhos já realizados que estão impressos em meios digitais e, desta forma, selecionar estudos relevantes para posterior discussão do tema.

Os levantamentos de dados foram na plataforma Periódicos da Capes e site da revista QNESC, utilizando os descritores "Química", "Agrotóxicos e Aprendizagem" "Agrotóxicos e Ensino", e "Agrotóxicos e Ambiente, compreendendo o período de 2010 a 2020.

\section{RESULTADOS}

Foram identificados dez (10) artigos (Tabela 1) e selecionados cinco (05) que atenderam ao escopo da pesquisa (Cavalcanti et al., 2010; Braibante e Zappe, 2012; Sá-Oliveira et al., 2015; Souza et al., 2015; Mello et al., 2018; Pozzebon et al., 2018; Salgado et al., 2018; Silva e Leão, 2018; Ribeiro et al., 2020; Vargas et al., 2020).

RC: 78586

Disponível em: https://www.nucleodoconhecimento.com.br/educacao/nivel-medio 
Tabela 1 Mostra o título dos artigos identificados, seus autores, e as revistas e anos nas quais foram publicados.

\begin{tabular}{|c|c|c|c|}
\hline & TÍTULO & (AUTOR(ES) / ANO) & $\begin{array}{c}\text { PLATAFORMA OU } \\
\text { REVISTA } \\
\end{array}$ \\
\hline 1 & $\begin{array}{c}\text { Contradições Presentes na Percepção de } \\
\text { Estudantes Secundaristas de uma Escola Estadual } \\
\text { do Municipio de Campo Verde-MT sobre o } \\
\text { Tema Agrotóxicos }\end{array}$ & (Ribeiro et al. , 2020). & Revista Prática Docente \\
\hline 2 & $\begin{array}{c}\text { Método de Resolução de Problemas no Ensino } \\
\text { Médio: uma proposta interdisciplinar abordando o } \\
\text { Tema agrotóxico. }\end{array}$ & (Salgado et al., 2018) & Revista Prática Docente \\
\hline 3 & $\begin{array}{l}\text { Agrotóxicos no Ensino de Química: proposta } \\
\text { contextualizada através de um jogo didático }\end{array}$ & (Mello et al., 2018) & $\begin{array}{l}\text { Revista Eletrônica Ludus } \\
\text { Scientiae. }\end{array}$ \\
\hline 4 & $\begin{array}{c}\text { Em Julgamento, o Uso de Agrotóxicos: estratégia } \\
\text { utilizada para ensinar quimica a estudantes do } 3^{\circ} \\
\text { ano do ensino médio de uma escola do campo }\end{array}$ & (Silva e Leão, 2018) & Revista Prática Docente \\
\hline 5 & $\begin{array}{c}\text { A Utilização de Tics no Desenvolvimento da } \\
\text { Temática "agrotóxico": um quiz como ferramenta } \\
\text { de apoio pedagógico }\end{array}$ & (Vargas et al., 2020) & $\begin{array}{c}\text { ENCITEC - Ensino de } \\
\text { Ciências e Tecnologia em } \\
\text { Revista } \\
\end{array}$ \\
\hline 6 & $\begin{array}{c}\begin{array}{c}\text { Educação Ambiental no Ensino Médio: } \\
\text { preservação, conscientização e busca pelo } \\
\text { conhecimento }\end{array} \\
\end{array}$ & (Pozzebon et al., 2018) & $\begin{array}{c}\text { Extensio: R. Eletr. de } \\
\text { Extensão }\end{array}$ \\
\hline 7 & $\begin{array}{c}\text { Agrotóxicos: Uma Temática para o Ensino de } \\
\text { Química }\end{array}$ & (Cavalcante et al., 2010) & QNESC \\
\hline 8 & $\begin{array}{l}\text { Proposta Educativa Utilizando o Jogo RPG } \\
\text { Maker: Estratégia de Conscientização e de } \\
\text { Aprendizagem da Química Ambiental }\end{array}$ & (Souza et al., 2015). & Revista Quimica Holos \\
\hline 9 & $\begin{array}{c}\text { A Agroecologia na Percepção de Alunos de } \\
\text { Ensino Médio de Quatro Escolas Públicas na } \\
\text { Cidade de Macapá-Amapá }\end{array}$ & (Sá-Oliveira et al., 2015) & Biota Amazônia \\
\hline 10 & A Quimica dos Agrotóxicos & (Braibante e Zappe, 2012) & QNESC \\
\hline
\end{tabular}

O primeiro artigo que traz como título: Contradições Presentes na Percepção de Estudantes Secundaristas de uma Escola Estadual do Município de Campo VerdeMT sobre o tema Agrotóxico, com uma metodologia qualitativa, teve como objetivo principal a elaboração de um livro paradidático sobre conceitos de Química e Biologia. Articula conhecimentos científicos com fenômenos presentes no dia a dia dos estudantes. A pesquisa foi realizada com quarenta e seis estudantes do ensino médio da Escola Estadual Ulisses Guimarães. O trabalho apresentou resultados satisfatórios, sobre o tema em estudo, afirmam os autores, mas foi observado que os estudantes tinham contradições em suas percepções sobre a temática.

RC: 78586

Disponível em: https://www.nucleodoconhecimento.com.br/educacao/nivel-medio 
O estudo que tem como título: Método de Resolução de Problemas no Ensino Médio: uma proposta interdisciplinar abordando o tema agrotóxico e teve como propósito averiguação das formas de sequência didática efetuada para aprendizagem de conteúdos conceituais e atitudinais relativos às questões ambientais e com metodologia qualitativa. Foi desenvolvido com trinta e cinco discentes do $3^{\circ}$ ano do ensino médio. Os resultados demonstraram que houve um aumento na conscientização dos estudantes sobre a temática abordada e as consequências que estes agroquímicos podem causar à saúde humana, ambiental.

A pesquisa que tem como tema Agrotóxico no Ensino de Química: proposta contextualizada através de um jogo didático teve como objetivo investigar as potencialidades e as vantagens da aplicação de um jogo didático para o ensino de Química com a temática agrotóxica, como estratégia para o ensino de estudantes de uma escola pública de ensino médio, com uma abordagem quantitativa. Os resultados dos estudos demonstraram-se satisfatórios, e ratificam ainda os pesquisadores que a aplicação de um jogo didático com esta temática contribui para um aprendizado mais significativo e auxilia na articulação teórico-prática.

O trabalho intitulado Em Julgamento, o Uso de Agrotóxicos: estratégia utilizada para ensinar química a estudantes do $3^{\circ}$ ano ensino médio de uma escola do campo teve como meta descrever a simulação de um júri sobre o uso de agrotóxicos como método de ensino em química. Utilizou uma abordagem qualitativa e relatos de experiências. Com o desenvolvimento e execução da pesquisa os estudos apontaram resultados positivos, na premissa que o envolvimento dos estudantes e a busca por informações foram de extrema valia para a construção e compreensão do tema em questão, a partir da realidade do cidadão que vive no campo.

A pesquisa com tema: A Utilização de Tics no Desenvolvimento da Temática "agrotóxico": um quiz como ferramenta de apoio pedagógico consistiu-se em relatar uma atividade desenvolvida e aplicada por bolsistas do Programa Institucional de Bolsas de Iniciação à Docência (PIBID), com ênfase a importância e eficácia em utilizar a tecnologia como um recurso pedagógico por meio do jogo Quiz Agrotóxico.

RC: 78586

Disponível em: https://www.nucleodoconhecimento.com.br/educacao/nivel-medio 
A metodologia utilizada foi por meio de jogos com o uso de tecnologias feitas no software PowerPoint. Com a conclusão das atividades os resultados mostraram-se satisfatórios, na medida em que os estudos constataram a importância das tecnologias como meio de acesso e reforço no conteúdo explanado.

A investigação intitulada Educação Ambiental no Ensino Médio: preservação, conscientização e busca pelo conhecimento teve como propósito abordar a educação ambiental para o ensino médio em uma escola em Itaqui- Rio Grande do Sul. Sua como meta foi estimular a conscientização, preservação e busca pelo conhecimento com uma metodologia qualitativa com a organização de palestras técnicas e educativas para os discentes. Os resultados mostraram que $34 \%$ a $56 \%$ não conheciam os temas e 95\% a 100\% demonstrou que a comunidade não tinha qualquer conhecimento sobre o assunto "problemas ambientais que afetavam a região".

O estudo que tem como tema Agrotóxicos: uma Temática para o Ensino de Química teve como objetivo descrever uma intervenção que foi desenvolvida com estudantes do $1^{\circ}, 2^{\circ}$ e $3^{\circ}$ ano do ensino médio. Com uma abordagem qualitativa, o trabalho envolveu os discentes na construção de conceitos da Química com a temática agrotóxicos. As estratégias foram divididas em momentos diferentes, a saber: visualização de imagens, levantamento de concepções prévias dos discentes, estudo do meio, seminários, leituras, interpretação e discussão de textos, paineis integrados, trabalhos em grupo e experimentos. Os resultados da investigação demonstraram resultados exitosos pois, com a participação mais ativa dos discentes, foi mais proveitoso à avaliação, promovendo, desta forma, uma maior participação e socialização das ideias, permitindo assim o estudante atuar de forma significativa na construção da aprendizagem.

A investigação com o tema: Proposta Educativa Utilizando o Jogo RPG Maker: Estratégia de Conscientização e de Aprendizagem da Química Ambiental objetivou propor um objeto de aprendizagem baseado no RPG Maker, que é um software educativo, como forma de conscientização e aprimoramento do ensino de Química 
ambiental para discentes do ensino médio. Os autores optaram por fazer um estudo de caso sobre o assunto, aplicado em duas turmas de terceiro ano do ensino médio. Os resultados demonstraram que o software tornou o trabalho do docente mais interessante e, no que tange aos discentes, foi observado que a ferramenta se tornou uma grande estratégia para o processo de ensino-aprendizagem, pois a aula tornou-se mais dinâmica, interativa e interessante, notando indícios de uma postura mais reflexiva por parte dos estudantes.

O artigo que tem como tema: A Agroecologia na Percepção de Alunos de Ensino Médio de Quatro Escolas Públicas na Cidade de Macapá-Amapá teve como meta verificar a percepção ambiental de alunos do $3^{\circ}$ ano do ensino médio de quatro escolas públicas estaduais e abordagem qualitativa e quantitativa. Com a execução da pesquisa os resultados apontaram que a maioria dos estudantes sequer conheciam o tema agroecologia, mas que de alguma forma executavam tais práticas, mesmo sem saber. Foi constatado que uma parcela dos entrevistados não tinha nenhum interesse pela temática em questão, bem como suas consequências ao meio ambiente e à saúde das pessoas. Também foi identificado em uma parcela maior preocupação com o plantio de soja na região, desmatamento e uso de agrotóxicos nas plantações. Concluiram assim, que a maioria destas escolas não trabalham agroecologia e não difundem a filosofia agroecológica.

O estudo com tema: A Química dos Agrotóxicos objetivou descrever a história dos agrotóxicos, relação com a disciplina Química, bem como suas consequências ao meio ambiente e ao trabalhador utilizando uma metodologia qualitativa. A partir de seus resultados, orienta o docente a utilizar a temática em suas aulas, utilizando assim, diferentes estratégias que possam contextualizar o ensino de Química aos Agrotóxicos que pode ser trabalhado em todas as séries do ensino médio.

\section{DISCUSSÃO}

A formação e forma de atuar do docente estão intrinsecamente relacionadas com o cenário educacional atual. No viés, que o uso de temáticas que têm relação com o

RC: 78586

Disponível em: https://www.nucleodoconhecimento.com.br/educacao/nivel-medio 
cotidiano pode ser um alicerce significativo no aprendizado dos discentes. Enfatizase ainda que os educadores ajudam a escrever a história do país e que de certa forma são decisivos na construção de futuros cientistas. Assim, devemos fazer do ensino uma linguagem que possa favorecer o entendimento de mundo para os estudantes (Chassot, 2000).

Foi observado que cinco das dez pesquisas (artigos 3, 4, 5, 7 e 10) (Tabela1) selecionadas correlacionaram a temática estudada em suas práticas metodológicas, e no que se refere aos trabalhos não selecionados foi notado que mesmo citando o ensino de Química em alguns pontos de suas pesquisas, o que se observou foi que durante a execução de seus estudos não relacionaram em seus métodos.

No estudo 03 que envolveu conceitos da química e meio ambiente, através da temática agrotóxicos, foram introduzidos conteúdos que são trabalhados nas aulas de química como, por exemplo, nomenclaturas das moléculas presentes nos agrotóxicos (Mello et al., 2018). Esta correlação é importante pois parece existir poucos estudos correlacionando a química com a resolução e prevenção de problemas ambientais (Leal e Marques, 2008).

No que tange a pesquisa 04, a simulação de um júri sobre o uso de agrotóxicos na perspectiva de ensinar química a estudantes do terceiro ano de uma escola do campo foi uma estratégia que possibilitou discutir conceitos como estrutura das substâncias presentes nos agrotóxicos (Silva e Leão, 2018). O ensino utilizando a correlação do cotidiano parece surtir maior efeito na aquisição do conhecimento na área de ciências da natureza (Carmo et al., 2021).

O estudo 05 relata um método de aprendizagem que foi a utilização de TICS por meio de um jogo denominado QUIZ por meio do software power point foram abordadas questões discursivas de química presentes no Exame Nacional do Ensino Médio (ENEM) (Vargas et al., 2020). Os discentes que pretendem ingressar no ensino superior brasileiro utilizam este exame. Portanto um ensino que utilize

RC: 78586

Disponível em: https://www.nucleodoconhecimento.com.br/educacao/nivel-medio 
questões deste pode aumentar os subsídios para que o estudante tenha sucesso no seu ingresso no terceiro grau (Gortz et al., 2021).

O trabalho 07 aborda uma intervenção didática envolvendo a temática agrotóxicos e o conteúdo do ensino de química como ácidos, bases, e funções orgânicas. Isso pareceu envolver os discentes na construção de seus próprios conhecimentos (Cavalcanti et al., 2010). As intervenções didáticas são instrumentos que aumentam a contextualização de assuntos e, consequentemente, a apreensão do conhecimento, sendo utilizadas em diversos componentes do ensino .(Bedin, 2019).

O artigo 10 descreve a história dos agrotóxicos, correlacionando a temática ao ensino de química do primeiro, segundo e terceiro anos. Foi organizada uma tabela de conteúdos que o docente poderá utilizar para lecionar, associando a temática abordada a química (Braibante e Zappe, 2012). Estudar esta história ajuda a aprofundar-se na interligação do agrotóxico, um produto químico, e as considerações acerca da sua influência no ambiente. A apropriação científica dá ao estudante estrutura para entender as consequências do seu uso e as maneiras possíveis de utilização sustentável, mesmo em pequenos ambientes como o doméstico (Moraes et al., 2011).

\section{CONCLUSÕES}

A observação deste breve levantamento permite concluir que:

- O ensino de química em turmas de segundo grau pode e deve estar relacionado a área da pesquisa e da divulgação científica;

- Há diversas ferramentas didáticas que possibilitam maneiras mais assertivas relacionadas ao ensino de química;

- Relacionar o conteúdo de química a assuntos interdisciplinares e específicos, como agrotóxicos, pode auxiliar a melhor compreensão dos conteúdos de química em estudantes do ensino médio.

$\mathrm{RC}: 78586$

Disponível em: https://www.nucleodoconhecimento.com.br/educacao/nivel-medio 


\section{REFERENCIAS}

BEDIN, E. Filme, experiência e tecnologia no ensino de ciências química: Uma sequência didática. Revista de Educação, Ciências e Matemática, v. 9, n. 1, p. 101-115, 2019.

BRAIBANTE, M. E. F.; ZAPPE, J. A. A Química dos Agrotóxicos. QUímICA NOVA NA ESCOLA, v. 34, n. 1, p. 10-15, 2012.

CARMO, D. R. D. et al. A física no enem e no curso técnico de química do instituto federal do amapá (IFAP): Uma comparação curricular. Revista Científica Multidisciplinar Núcleo do Conhecimento, v. 3, p. 80-88, 2021. Disponível em: < https://www.nucleodoconhecimento.com.br/educacao/fisica-no-enem >.

CAVALCANTI, J. A. et al. Agrotóxicos: Uma Temática para o Ensino de Química. QUÍMICA NOVA NA ESCOLA, v. 32, n. 1, p. 31-36, 2010.

CHASSOT, A. Alfabetização científica: questões e desafios para a educação. ljuí: Unijuí, 2000. 434 p.

GORTZ, J. S. et al. Química do ensino médio técnico e enem: Uma comparação curricular. Revista Científica Multidisciplinar Núcleo do Conhecimento, v. 3, p. 89-99, 2021. Disponível em: < https://www.nucleodoconhecimento.com.br/educacao/comparacao-curricular $>$.

HODSON, D. Realçando o papel da ética e da política na educação científica. In: ROSA, G. M. G. F.;RETORTA, N. N. N., et al (Ed.). Questões sociocientíficas fundamentos, propostas de ensino e perspectivas para ações sociopolíticas. Salvador BA: Editora EDUFBA,, 2018. p.32.

LEAL, A. L.; MARQUES, C. A. O Conhecimento Químico e a Questão Ambiental na Formação Docente. QUÍMICA NOVA NA ESCOLA, n. 29, p. 30-33, 2008.

RC: 78586

Disponível em: https://www.nucleodoconhecimento.com.br/educacao/nivel-medio 
LEITE, B. S. Tecnologias no Ensino de Química: teoria e prática na formação docente. Curitiba PR: Appris, 2015. 365p.

MELLO, L. F.; FONSECA, E. M. D.; DUSO, L. Agrotóxicos no ensino de química: Proposta contextualizada através de um jogo didático. Revista Eletrônica Ludus Scientiae(RELuS), v. 2, n. 1, p. 76-90, 2018.

MORAES, P. C. et al. Abordando agrotóxico no ensino de química: Uma revisão. REVISTA CIÊNCIAS\&IDEIAS, v. 3, n. 1, p. 1-15, 2011.

MOREIRA, A. M.; SCHITTLER, D. Laser de Rubi: uma abordagem baseada em unidades de ensino potencialmente significativas (UEPS). Revista Brasileira de Ensino de Ciência e Tecnologia, v. 9, n. 3, p. 03-04, 2016.

MOREIRA, M. A.; MASINI, E. F. S. A Aprendizagem Significativa: a teoria de David Ausubel. São Paulo SP: Moraes, 1982.

POZZEBON, B. C. et al. Educação ambiental no ensino médio: Preservação, conscientização e busca pelo conhecimento. Extensio: R. Eletr. de Extensão, v. 15, n. 28, p. 64-76, 2018.

RIBEIRO, D. T. M.; MESSIAS, C. G. G.; CRUZ, D. N. Contradições presentes na percepção de estudantes secundaristas de uma escola estadual do município de campo verde-MT sobre o tema agrotóxicos. Revista Prática Docente, v. 5, n. 1, p. 392-394, 2020.

SÁ-OLIVEIRA, J. C.; VASCONCELOS, H. C. G.; SILVA, E. S. A Agroecologia na Percepção de Alunos de Ensino Médio de Quatro Escolas Públicas na Cidade de Macapá-Amapá. Biota Amazônia v. 5, n. 3, p. 98-107, 2015.

SALGADO, M. D. T.; PASSOS, G. C.; RIBEIRO, A. C. D. Método de Resolução de problemas no ensino médio: uma proposta interdisciplinar abordando o tema agrotóxicos. Revista Prática Docente, v. 3, n. 2, p. 646-647, 2018.

RC: 78586

Disponível em: https://www.nucleodoconhecimento.com.br/educacao/nivel-medio 
SANTOS, W. L. P. D.; SCHNTZLER, R. P. Educação em Química: Compromisso com a cidadania. Ijuí: Editora Unijuí, 2010. 144p.

SILVA, G. P. D.; LEÃO, M. F. Em julgamento, o uso de agrotóxicos: Estratégia utilizada para ensinar química à estudantes do $3^{0}$ ano ensino médio de uma escola do campo. Revista Prática Docente, v. 3, n. 2, p. 610-624, 2018.

SOUSA, G. L.; SIMÕES, A. S. M. Uma Proposta de Aula Experimental de Química para o Ensino Básico Utilizando Bioensaios com Grãos de Feijão (Phaseolos vulgaris). Quím. nova esc, v. 38, n. 1, p. 79-83, 2016.

SOUZA, T. V. D. P. et al. Proposta Educativa Utilizando o Jogo RPG Maker: Estratégia de Conscientização e de Aprendizagem da Química Ambiental. Proposta Educativa Utilizando o Jogo RPG Maker: Estratégia de Conscientização e de Aprendizagem da Química Ambiental, v. 8, p. 98-112, 2015.

VARGAS, A. F. et al. A Utilização de Tics no Desenvolvimento da Temática "agrotóxico": um quiz como ferramenta de apoio pedagógico. In: BOER, N.;KRAUSE, J. C., et al (Ed.). Educação científica, tecnológica e inclusiva. Cruz Alta: Editora llustração, 2020. p.271-274.

Enviado: Março, 2021.

Aprovado: Março, 2021.

RC: 78586

Disponível em: https://www.nucleodoconhecimento.com.br/educacao/nivel-medio 